This is an electronic reprint of the original article. This reprint may differ from the original in pagination and typographic detail.

Please cite the original version: L. Wallenius, T. Lehto, T. Votkin, M. Halsas (2018) Online Platform for Digital Multi-Disciplinary Language Learning, ICERI2018 Proceedings, pp. 1265-1271.

doi: $10.21125 /$ iceri.2018.0129 


\title{
ONLINE PLATFORM FOR DIGITAL MULTI-DISCIPLINARY LANGUAGE LEARNING
}

\author{
L. Wallenius ${ }^{1}$, T. Lehto ${ }^{2}$, T. Votkin ${ }^{3}$, M. Halsas ${ }^{1}$ \\ ${ }^{1}$ Haaga-Helia University of Applied Sciences (FINLAND) \\ ${ }^{2}$ Laurea University of Applied Sciences (FINLAND) \\ ${ }^{3}$ Aalto University (FINLAND)
}

\begin{abstract}
Our paper discusses digitalization of language learning and the creation of an open language learning platform for learning professional Swedish. The platform is being developed in one of the teacher teams in DIGIJOUJOU project, a national development project for digitalizing second language learning in higher education in Finland and financed by the Ministry of Education. The team represents three institutions: Aalto University, Laurea University of Applied Sciences and Haaga-Helia University of Applied Sciences.
\end{abstract}

The objective of the paper is to explore possibilities developed for digital learning as well as a platform aimed at students and teachers. The platform caters multi-disciplinary learning with task-based activities for intermediate level students in higher education. It may be incorporated into institutional tuition and it offers a platform for students to select activities suitable for their personal learning plans and university curricula. The open platform comprises various task-based activities within six topic areas and additional support pages for students and teachers. The underlying methods and theories are those of task-based learning, flipped learning and blended learning.

The platform and its activities will be open source and participants use various digital learning and communication tools in its implementation. Students are empowered to tailor the courses for their own needs, topics and tasks. They select tasks relevant for their future profession and search for branchrelated texts and readings. They work individually and in group, synchronously and asynchronously, on-line and face-to-face (blended learning). In the future the platform might be used by multidisciplinary groups.

The innovative aspect of this platform lies in benefiting learners and instructors as an activity and instruction bank. It is noteworthy that the platform must be combined with a university course with an instructor and a learning environment. Learners may submit their work on the university platform and instructors then coach and assess them in their learning tasks. Doing this they also sign in and participate in online discussion groups, online meetings and discussions to present and discuss their own and other students' work. Hence self and peer assessment are involved.

Keywords: digital learning, flipped learning, task-based learning, Swedish as a second language, language, learning, open-source materials.

\section{INTRODUCTION}

This paper discusses on-going project work of a team in DIGIJOUJOU, a three-year national development project for digitalizing second language learning financed by the Ministry of Education, Finland. As many as 12 universities and 52 university lecturers teaching Swedish or Finnish as a second language are taking part in the project. The project has three main targets: to develop new digital pedagogy and blended learning/e-learning curricula, to create flexible study paths for university students as well as to increase national collaboration and build higher education crossovers for both lecturers and students.

The higher education institution network in Finland includes universities (14) and universities of applied sciences (23). Universities focus on scientific research and education based on it. Universities of applied sciences, on the other hand, offer a pragmatic education that responds to work life needs. Universities of applied sciences are mainly multidisciplinary regional higher education institutions whose activities highlight their connection to work life, while the basic task of the universities is to engage in scientific research and provide the highest level of education based on it. [1] In DIGIJOUJOU-project both institutions are represented, as all students have obligatory Finnish and 
Swedish studies offered in their degree programmes, and thus the need to develop flexible learning and guidance in these languages for the future labour market is evident in both institutions.

The DIGIJOUJOU-project aims at an overall pedagogical development. The project explores the present stage of digital learning, digital competences needed by language teachers, the present digital competence of language teachers, the development of digital study materials, as well as teacher support for students' individual learning. It is evident that language teachers in higher education need shared discussions and joint efforts to understand digital literacy and its implementations in learning and teaching. The participants of DIGIJOUJOU-project aim to have better mutual understanding of all mentioned above.

The participants of the project were divided into groups of 3-4, all from different institutions, according to personal interest in the project targets. During the project the groups are engaged in working with minor development tasks to broaden the digital thinking models, in testing new digital tools and in discussing and testing new digital pedagogy. During seminars and workshops new ideas are shared between groups and feedback is collected. Between the meetings there are webinars presenting innovations and good practices by specialists outside the project as well as online meetings with the steering group members to secure the information flow. Participants of the project write a blog about the proceedings and the project has a web page gathering the overall information. The outcome of each group's work is to create new blended learning pedagogy using multi-media methods for teaching and guidance in the national language subjects. The outcome may be study material or pedagogical innovation, and the outcome of the project will be published on an open-source platform by the end of the year 2019 .

Our project team representing three institutions (Aalto University, Haaga-Helia University of Applied Sciences and Laurea University of Applied Sciences) is creating an open language learning platform for learning professional Swedish. The platform caters multi-disciplinary learning with task-based activities for intermediate level students in higher education, both in universities and universities of applied sciences. The platform leans on blended learning, flipped learning, task-based learning as well as a strong connection to work life needs. The platform is presented in detail in chapter 3 , and the pedagogical solutions of the platform are discussed in chapter 2.

\section{METHODOLOGY AND PEDAGOGICAL FRAMEWORK}

The platform "Svenskstudier i buffétformat" (Buffet Model for Swedish Studies, translation) [2] is based on the following three language learning approaches: task-based language learning, flipped learning and blended learning. The platform has also been influenced by Communicative Language Teaching and content-based instruction. This chapter discusses the connection between the different approaches and the tasks on our platform.

Our approach belongs under the umbrella of Communicative Language Teaching (CLT). The aim of CLT is to teach communicative competence. Significantly, the students learn communicative skills that are necessary in the work life. In accordance with the principles of CLT, the goal is to prioritize the students' needs and give the students the freedom to choose topics that are interesting and relevant to them. The central idea of CLT is that learning happens through peer input and in interaction with fellow students [3]. Communicative competence entails, among other things, knowledge of how to use language for different purposes, the ability to understand and to produce different types of texts (e.g. reports, interviews) [4]. As this is also one of our aims, we offer many different types of tasks, which allow the learner to practice producing various types of texts.

Content Based Instruction (CBI) entails learning the target language through content. Learning is built around a relevant content rather than a linguistic syllabus. [5]. Thus, the language is more of a tool that is used to reach a goal, not the goal itself. In Content Based Instruction (CBI), motivation is regarded as a very important factor, and the idea is to provide the learners with motivating tasks. Significantly, stimulating content is a key factor in motivating students. In our tasks, the students are encouraged to choose a perspective that is interesting and relevant to them, and to seek information from similar sources. In $\mathrm{CBI}$ the aim is not to study isolated language fragments, but to learn the language in a specific context. When students are working on the content, e.g. when searching information and producing output, they have an opportunity to hear and read, as well as write or speak the target language. The focus throughout the process is on the content and not on the language itself, thus the language learning is a byproduct of the process. In addition, CBI is student- centered as opposed to teacher-centered. [6] 
Task-Based Language Learning (TBLL) is a category under the concept of Content Based Instruction [7] If not referring to applied linguistics, a task can be anything concrete that someone does, such as painting a wall, doing groceries or buying a flight ticket. When an applied linguist refers to task-based learning, it means completing something by using the target language as a tool of communication. [8] It could be booking a train ticket or visiting a doctor. Evidently, there is a clear difference between a task and exercise. An exercise can be drilling one aspect of language, like grammar or pronunciation, but it does not fulfill the description of a linguistic task. Ellis [8 ibid.] emphasizes the importance of social interaction and communication in Task Based Language Learning. It/ became widely known through N. Prabhu and his work in India where he observed that students learned the target language as well when working with concrete tasks as when focusing on the linguistic aspects of the language, like grammar [9]. The platform consists of tasks that the students do individually, in pairs or in groups. The tasks can be done regardless of time and space and they can be completed in the learner's own pace.

Another language learning theory applied in this paper is flipped learning. A central concept in flipped learning is to promote student autonomy, so that the student takes more responsibility for the learning process, however, on the other hand it regards learning as a social event [10]. In practice flipped learning means that the students work on a certain theme and with material related to it at home prior to classroom teaching [11]. It is often understood as becoming acquainted with material that the teacher recommends, such as texts, audios or videos or seeking interesting information independently. Even the phase of processing information can take place before coming to class. In the classroom, the idea is to discuss, and present phenomena studied at home. Talbert emphasis that flipped learning is much more than just using certain techniques, and he sees it rather as a methodology (ibid.) Notably, the tasks available on the platform are all suitable for flipped learning, since the idea is that the students work on a task at home, and then present and discuss it in class with other students and the teacher.

Blended learning means that the student is doing part of the work individually and part of it face to face in the classroom. [12]. It is important that the student has control over when and where to work and at what pace. The fact that students are more in charge with their own learning and able to control it, is an important aspect of blended learning. This is one of the factors distinguishing it from technologyrich instruction. The tasks in our platform are designed so that the student can do part of them by working online. The instructions for the tasks are available online and encourage the students to use online sources when searching for information. The students can thus use online tools to process the data and they are also able to share the outcomes online. Finally, the students are required to present their outcomes in the classroom (face-to-face or virtual) and discuss their work with their peers.

\section{Blending Learning Models}

Blended learning can be grouped into six distinct models that vary by teacher roles, physical space, delivery methods, and scheduling. However, as new versions of blended learning are developed, the relationships between these models will evolve. Presented below is a preliminary classification of the blended learning models currently in use.

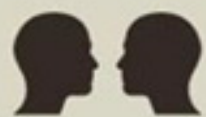

Face-to-Face Driver

Face-to-face teachers deliver most of the curriculum. A physical teacher employs online learning in a technology lab or the back of the classroom to supplement.

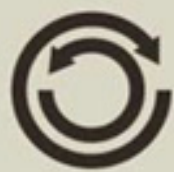

\section{Rotation}

Within a given course, students rotate on a fixed schedule between self-paced online learning and sitting in a classroom with a face-to-face teacher.

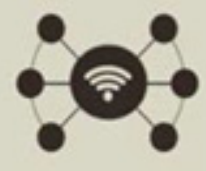

Flex

An online platform delivers most of the curriculum. Teachers provide on-site, as-needed support through in-person tutoring or small group sessions.

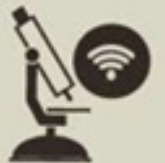

Online Lab

An online platform delivers the entire course, but in a brick-and-mortar location. Often, students who participate in an online lab program also take traditional courses.

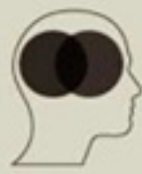

\section{Self-Blend}

Students choose to take remote online courses to supplement their school's traditional curriculum. This model of blended learning is extremely popular among high school students.

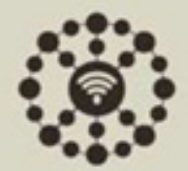

Online Driver

An online platform and teacher deliver all the curriculum. Students work remotely, and face-to-face check-ins are either available or mandatory.

Figure 1. Rise of the K-12 Blended Learning: Profiles of Emerging Models by Innosight Institute and Charter School Growth Fund 
Teaching with Technology site [13] discusses different types of models for blended learning and among them a six-model profile as presented in Figure 1. These six models include Face-to-Face Driver, Rotation, Flex, Online Lab, Self-Blend and Online Driver. Our platform might cater the following models: Rotation, Self-Blend, Flex and Online Driver.

In Rotation the learning is a hybrid of self-learning online and face-to-face meetings, with teachers scheduling the phases and with the platform holding a supportive role. In the Self-Blend model learners supplement their curricula set courses with self-selected online materials on the portal. Furthermore, the platform might cater for Self-Blended learning for e.g. for extra-curricular and freechoice studies. The Flex model, on the other hand, gives control for the learners to select contents and study online with instructor support when needed. Students may also choose the method of delivery i.e. video, audio, written report or multi-modal presentation in virtual or face-to-face class. Students on preparatory courses might benefit form Flex blended-learning when e.g. learners need to review grammar and everyday vocabulary prior to taking language courses on specific professional contents. However, some lower-intermediate level learners might struggle studying on their own online. Online Lab learning might be realized when students design their own course on the "Svenskstudier i buffetformat" platform and seek accreditation with their language instructor to gain credits.

\section{RESULTS}

This chapter discusses the contents of "Svenskstudier i buffétformat" platform, the choice of content management system, user feedback and ideas for further development.

\subsection{Multi-disciplinary learning contents and activities on the web}

The learning activities on the portal cater for many disciplines and they are designed with generic contents. The activities require branch-specific terminology in tasks such as reporting, presenting and analyzing processes and phenomena. It should be observed that the portal is static, in other words, no papers are submitted there, nor does any interaction take place on it. It is mainly used in combination with an institutional learning environment with instructor-student interaction and paper submissions.

Figure 2 demonstrates a Flex use of the platform explained in the following: The platform caters for various activities which students select according to curricula requirements. Students then choose various activities for their learning agreement which they submit for their teacher's approval. Once the agreement is approved, the teacher creates groups and gives the students access to their institutional learning platform with discussion forums and assignment submission. In the next phase, students study and produce their outcomes with digital tools. Some outcomes might be traditional papers, or alternatively, videos or infographics. Teachers might combine the online learning with face-to-face time for outcome presentations.

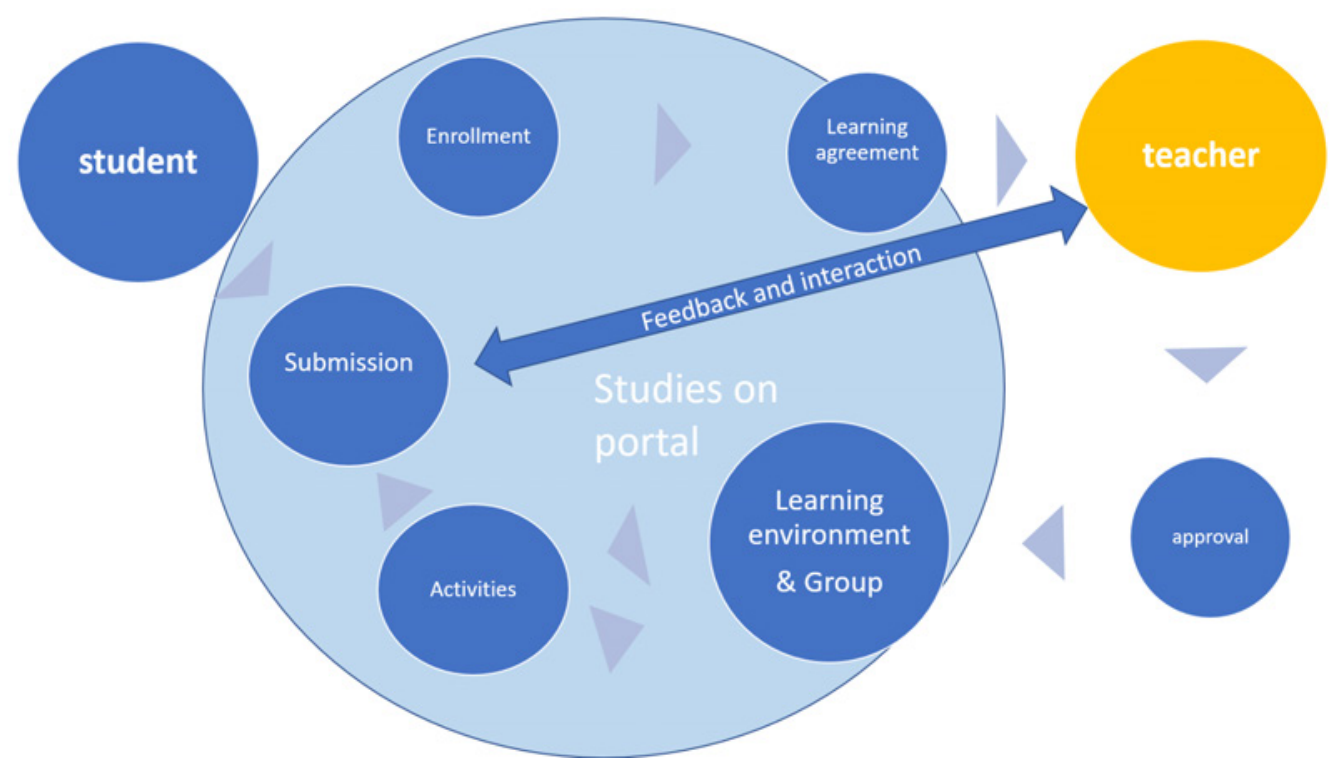

Figure 2. Flex blended learning and student-teacher interaction on the portal. 
Furthermore, instructors may create various combinations of online and class study, chats and virtual meetings. Naturally, virtual encounters and communication will cater for future work life competence and provide agility to cope with different electronic and other work environments. Additionally, the multi-disciplined study groups also serve as preparation for future work life where team work skills are required. Consequently, the learning has a social context as many of the activities are prepared in teams and at least presented and discussed in teams. This implies social learning, agility and taking quick decisions

The learning activities include flexibility and involve using and practicing various skills. The platform functions as an activity bank with instructions for students and teachers, providing ideas how to use it and how to combine it with their organizational learning environments.

\subsection{Flexible open-source platform as learning tool}

The objective is to offer innovative and flexible paths of study. The innovation lies in the ideas of how such a platform as "Svensksstudier i buffétformat" might be employed in courses across disciplines and institutions, as well as learning online in digital and in mobile environments. Most universities offer online studies and combinations or face-to-face and virtual studies on their institutional learning environments that require registration. Accordingly, such environments can be bureaucratic and nonflexible which might make studies more difficult. Further, many students prefer to use a mobile device in their studies. An open-source content management system with no log-in requirements appeared to be the best choice for the platform as it was free of charge. The system allowed to build a website that functions rather well with various operation systems and with mobile interface. Finally, the mobile interface was of importance as many students prefer to use their mobile devices in learning.

\subsection{User comments}

In August 2018 a group of teachers gave their feedback on the first version of the platform in a project seminar. The respondents found WordPress to be a well-functioning content management system. Moreover, the platform categories were found good, versatile and interesting for students as well as sufficiently generic to cater for various disciplines. They also found the instructions clear. One respondent would have liked to see more branch-related activities. Furthermore, they could use the platform as a part of their own courses to supplement other material and use it in combination with face-to-face tuition and for homework activities. Some thought they could use it on compulsory courses before specializing on branch-related activities, and to have students create course content together with the activities.

The respondents were also asked to list different pedagogical strengths of this kind of web-based activity bank. Attributes such as clarity, flexibility and especially accessibility came up in almost every answer and the respondents experienced these factors as most essential. One respondent added that teachers can easily control his/her own (and the students) workload while using this kind of stable and well-organized webpage. Some of the respondents brought up the importance of self-direction. They saw that students can smoothly create their own study paths and focus on the exercises they find out useful and meaningful, and work at own pace. Three respondents mentioned that a web-based material bank might be rather secure as platform and at the same time free from any IT-related regulations by the institutions. Some of the respondents also brought up sustainability as an important advantage of such a platform.

The respondents identified the following challenges: 1) users find the advertisement the service provider sends annoying and stops using it, 2) students starting to circulate their responses from one group and year course and university to another, 3) not being able to submit the work on the same platform and having to use at least another one and 4) difficulty to estimate how much time is needed for each activity. In terms of benefits, they believed that such a web-based platform might enhance flexibility and cooperation across universities in student perspective in that 1) the material is of the same standard in all universities, 2) flexibility of studies, 3) open-source material for anyone to access and that 4) it might prompt multi-disciplinary projects. Ideas given for the visual outlook and functionality of the platform were to increase clarity and simplicity as well as to diminish the amount of text while adding the number of pictures. Finally, the comments were positive in general and the respondents found the site agreeable and clear. Moreover, all the respondents were likely to use the platform and recommend it to their colleagues. 


\subsection{Further development}

In the future, the platform will be developed and tested further. Accordingly, the project team aims at developing the visual image, the contents, instruction pages with help of feedback to be collected.

Based on the feedback that was obtained in August 2018, the visual image will be enhanced with illustrations and charts making the platform more user-friendly. Also, video instructions and podcasts might be added, and some instructions will be given in Finnish and Swedish and possibly in other languages as well. Furthermore, the team will also take into account students with advanced language skills and involve industry partners in creation of work-related contents.

Piloting will take place in spring 2019 with 2nd and 3rd semester Bachelor students as part of the curricula in different disciplines with various models of blended-learning. The platform activities will also be tested for alternative implementations of curricula courses and for recognition of prior learning.

\section{CONCLUSIONS}

In conclusion, the platform being developed aims at enhancing flexible study paths and empowering students to choose their own study contents, time and place of their studies. Currently, the benefits of such a platform might be multi-disciplinary contents, cross-institutional learning groups, flexibility of time and space, self-directed learning and open source learning content management system.

The final version of the platform will be presented and distributed by the end of the year 2019, and the outcomes will be disseminated throughout higher education in Finland. The platform is open and free of charge for non-commercial purposes ( $\mathrm{CC}$ by $\mathrm{NC}$ ). The platform might not be updated once the project closes, however, the subsequent afterlife is yet to be planned.

\section{ACKNOWLEDGEMENTS}

The authors wish to express their gratitude to the DIGIJOUJOU project and our home institutions for offering the opportunity and resources to develop digitalization of learning of Swedish as a second language.

\section{REFERENCES}

[1] Higher education and science. Ministry of Education. Retrieved from https://minedu.fi/en/highereducation-and-research

[2] Svensksstudier i buffétformat -Learning plattform URL:https://svenskstudieribuffetformat.wordpress.com

[3] W. Littlewood, Communicative language teaching: An introduction. Cambridge University Press, 1981.

[4] J.C. Richards, Communicative language teaching today. SEAMEO Regional Language Centre, 2005.

[5] J. Richards, T. Rodgers, Approaches and Methods in Language Teaching. Cambridge: Cambridge University Press, 2014.

[6] D. Brinton, "Content-based instruction". In D. Nunan (Ed.), Practical English Language Teaching. New York: McGraw Hill, 2003.

[7] Y. J. Basim, M. T. Yousif, "A Content- Based Instruction Versus Task-Based Approach to Teaching Legal English: An Experimental Study", In University of Sharjah Journal for Humanities \& Social Sciences, Volume 9, No. 3 pp. , 2012. Retrieved from http://www.sharjah.ac.ae/en/Research/spu/JournalHSS/Documents/V9/N3/Basim\%20Yahya\%2 OJasim.pdf 18.9.2018.

[8] R. Ellis, Task-based Language Learning and Teaching. Oxford: Oxford University Press, 2003.

[9] N.S. Prabhu, Second Language Pedagogy. Oxford: Oxford University Press, 1987.

[10] Toivola \& al. (2017), Flipped learning - Käänteinen oppiminen, Edita, 2017 
[11] R. Talbert, Flipped Learning - A Guide to Higher Learning Faculty. Stylus Publishing, LLC, 2017.

[12] Great Schools Partnership. 2013. Blended learning. Last accessed online 18.9.2018. Retrieved from http://edglossary.org/blended-learning/

[13] C. Maxwell, What blended learning is and isn't. Blended Learning Universe, 2016. Retrieved from https://www.blendedlearning.org/what-blended-learning-is-and-isnt/ 20.9.2018.

[14] Teaching with Technology. Online workshop series 2012-2013. Retrieved from https://teachingwithtech.Iss.wisc.edu/m3w1.htm. 21.9.2018.

\section{Figures}

- Figure 1. Rise of the K-12 Blended Learning: Profiles of Emerging Models by Innosight Institute and Charter School Growth Fund at Teaching with Technology. Online workshop series 20122013. Retrieved from https://teachingwithtech.Iss.wisc.edu/m3w1.htm. 21.9.2018.

- Figure 2. Flex blended learning and student-teacher interaction on the portal. Svensksstudier $\mathrm{i}$ buffetformat team. September 2018. 